\title{
From DiY to DiWO: from Crafting to Digital Collaboration
}

\section{SIGRADI2018 TECHNOPOLITICAS \\ xxii congresso da sociedade iberoamericana de gráfica digital 22th conference of the iberoamerican society of digital graphics $07|08| 09 \mid$ novembro|2018 iau usp | são carlos | sp br}

\author{
Paula Ramos Pacheco \\ Instituto de Arquitetura e Urbanismo IAU-USP | Brazil | paula.pacheco@usp.br
}

David M. Sperling

Instituto de Arquitetura e Urbanismo IAU-USP | Brazil | sperling@sc.usp.br

\begin{abstract}
Cultural changes based on recent development of information technologies suggests that knowledge could be spread with less control and greater accessibility, allowing the emergence of communities that launch alternatives like, for example, networks of laboratories for manufacturing. However, similar ambitions regarding the creation of alternatives to industrial production can be identified in the countercultural context of the 1960s and 1970s. This article traces some comparisons between these two historical moments with the goal of investigate how do-it-yourself (DiY) appears (again) in the design scene today as do-it-with-others (DiWO), establishing approximations and distances between two selected objects of study.
\end{abstract}

Keywords: Open Design; Collaboration; Do-it-yourself; Do-it-with-others; Maker Movement

\section{INTRODUÇÃO}

Mudanças culturais com base no desenvolvimento recente de tecnologias informacionais sugerem que o conhecimento possa ser difundido mundialmente com menor controle e maior acessibilidade, possibilitando o aparecimento de comunidades organizadas visando compartilhar o conhecimento e lançar alternativas às lógicas dominantes (por exemplo redes de laboratórios voltados à fabricação, digital ou não, FabLabs e MakerSpaces). No entanto, ambições semelhantes, no que diz respeito à criação de alternativas à produção industrial, podem ser identificadas no contexto contracultural das décadas de 1960-70. O artigo traça algumas comparações entre estes dois momentos históricos com o objetivo de investigar como, e sobre quais bases o faça-você-mesmo (do inglês, do-it-yourself, DiY) (re)aparece na cena do design na atualidade como o faça-com-os-outros (do inglês, do-it-with-others, DiWO), estabelecendo aproximações e distanciamentos entre dois objetos de estudo selecionados, considerados representativos de seu tempo.

Para tanto, o artigo exemplifica precedências participativas nas décadas de 1960 e 1970 no campo do design, para então trazer à tona equivalências no tempo presente, identificando aspectos que, juntamente com as tecnologias digitais e reorientações econômicas, permitam assinalar o envolvimento do usuário como agente definidor do processo de design.
Em um primeiro momento destacam-se, no campo do design nos anos 1960, os almanaques do tipo faça-vocêmesmo como veículos convenientes para a distribuição e promoção de saberes que se apresentavam como alternativa à lógica industrial. Toma-se, portanto, tal momento como horizonte para o tópico do envolvimento do usuário no processo de produção. Como objeto, é investigado o almanaque How to build your own living structures, de Ken Isaacs (1974), que oferece instruções aos leitores para a construção de mobiliários com materiais e instrumentos de baixo custo e fácil acesso.

Em um segundo momento, focado no cenário atual, aponta-se lógica similar em movimentos de ampliação do design que se classificam como pertencentes ao universo do design colaborativo, como comunidades que se organizam através da rede e assumem forte papel no contexto de ruptura de paradigmas e construção de novas propostas. Estas também tomariam como central a característica emancipatória de que dotam o consumidor quando se apropriam de ferramentas de projeto e produção que se pretendem independentes da cultura de massa. Aqui, toma-se como objeto de estudo a iniciativa WikiHouse, que reúne informações sobre a construção de residências sob a forma de código aberto, reunidas por profissionais (ou não) de diversos níveis e áreas (que respondem a premissas conhecidamente divulgadas pelos Movimentos Maker e DiWO), e gera alternativas para as formas usuais de se construir. 
Tendo em vista que as últimas décadas têm sido marcadas por crescentes desenvolvimentos de meios de projeto e produção, o exercício comparativo direcionado à identificação de potencialidades e limites dos dois objetos em questão, pretende colaborar com a investigação sobre como a emergência de questões relativas ao envolvimento do usuário - vinculada a mudanças culturais baseadas nas tecnologias de informação e comunicação - vem interferindo na disciplina do design, fomentando, por exemplo, o desenvolvimento de produtos de maneira colaborativa através de redes digitais.

\section{METODOLOGIA}

Esta pesquisa se pauta em aproximações qualitativas com base em:

Construção de referenciais teóricos acerca dos temas relativos a formas de produção, a precedências participativas nas décadas de 1960 e 1970 no campo do design, e a cultura do faça-você-mesmo emergente no período, bem como o levantamento de equivalências (teóricas e projetuais) no tempo presente;

Identificação de aspectos que, juntamente com tecnologias digitais e reorientações econômicas, permitam assinalar o envolvimento do usuário como agente definidor do processo de design;

Elaboração de fluxogramas organizadores dos processos de projeto e produção de cada objeto de estudo selecionado, de forma a sistematizar a leitura das pretendidas aproximações e distanciamentos entre os dois objetos, assim como possibilitar um exercício de comparação aos processos relativos à manufatura convencional.

\section{RESULTADOS}

\section{A DINÂMICA DO FAÇA-VOCÊ-MESMO NA DÉCADA DE 60}

O homem faz coisas por si mesmo desde antes que a história começa a ser registrada. Como apontam Stacey Kuznetsov e Eric Paulos (2010), o ato de consertar ou reutilizar ferramentas e materiais pode ser considerado como a base da sobrevivência humana ao longo da história, já que por centenas de anos as pessoas, a cargo de exemplo, repararam vazamentos, remodelaram suas casas e confeccionaram suas vestimentas sem que houvesse necessidade da contratação de profissionais especializados em encanamentos, construção, ou design para tal. Os mesmos autores apresentam o conceito de independência no âmbito da produção como oposição às tanto à lógica de produção em massa no contexto das sociedades modernas, quanto à da sociedade de consumo. Excetuadas as diferenças dessas duas, o que as une é a lógica do acesso aos objetos, feitos por outros, pela ação de compra.

Tendo em vista esse panorama em que itens e serviços podem ser facilmente adquiridos por meio de pagamento, o faça-você-mesmo é definido por Stacey Kuznetsov e Eric Paulos (2010) como qualquer criação, modificação ou reparo feitos sem o auxílio de profissionais pagos para tal, sendo que, portanto, a maioria das manifestações desse tipo não seriam motivadas por fins comerciais. Apesar de ser um termo que se aplica às origens inglesas do movimento, que se encontram no movimento punk e nas manifestações contraculturais características das décadas de 60 e 70, a cultura do faça-você-mesmo está classicamente ligada a ações de protesto e ativismo, bem como à apresentação de alternativas para atividades cotidianas.

É necessário compreender que a sociedade na qual se insere a contracultura nos anos 60 , ao menos nos Estados Unidos, berço do movimento, é qualificada pela presença de uma estrutura industrial avançada e por uma "pauta de consumo sempre renovada e num sistema essencialmente massificante." (Pereira, 1986, p.19). Assim, frente a um sistema tecnocrático, altamente baseado na racionalização e na objetividade, considerado pela classe jovem como repressivo e massificante, a ênfase que emprega às contestações será a do ato de fazer por si mesmo como afirmação de uma individualidade, visto que os sistemas de manufatura convencionais operam com base na produção seriada com objetivo de comercialização, como demonstrado no fluxograma da Figura 1.

Nesse contexto histórico, os manuais no estilo faça-vocêmesmo se mostraram o veículo ideal para distribuir amplamente os recursos da vida alternativa (Figura 2).

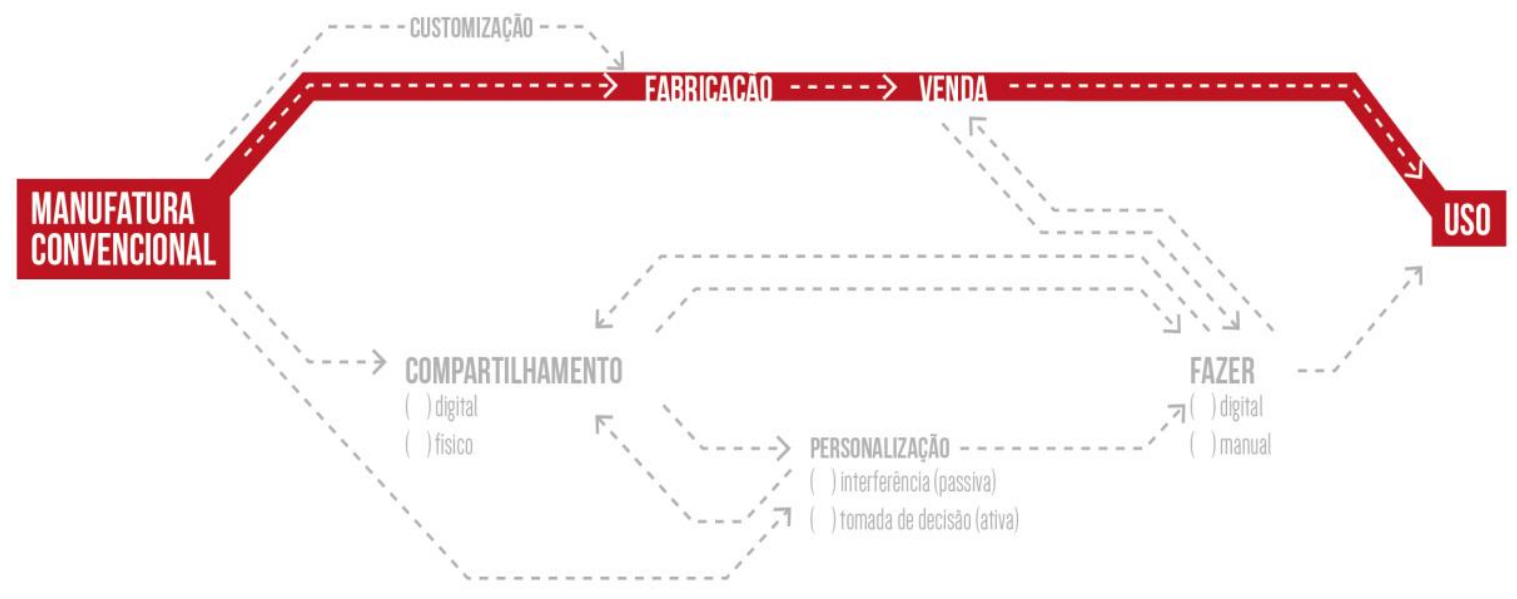

Figura 1: sistema de manufatura convencional. Fonte: autores. 


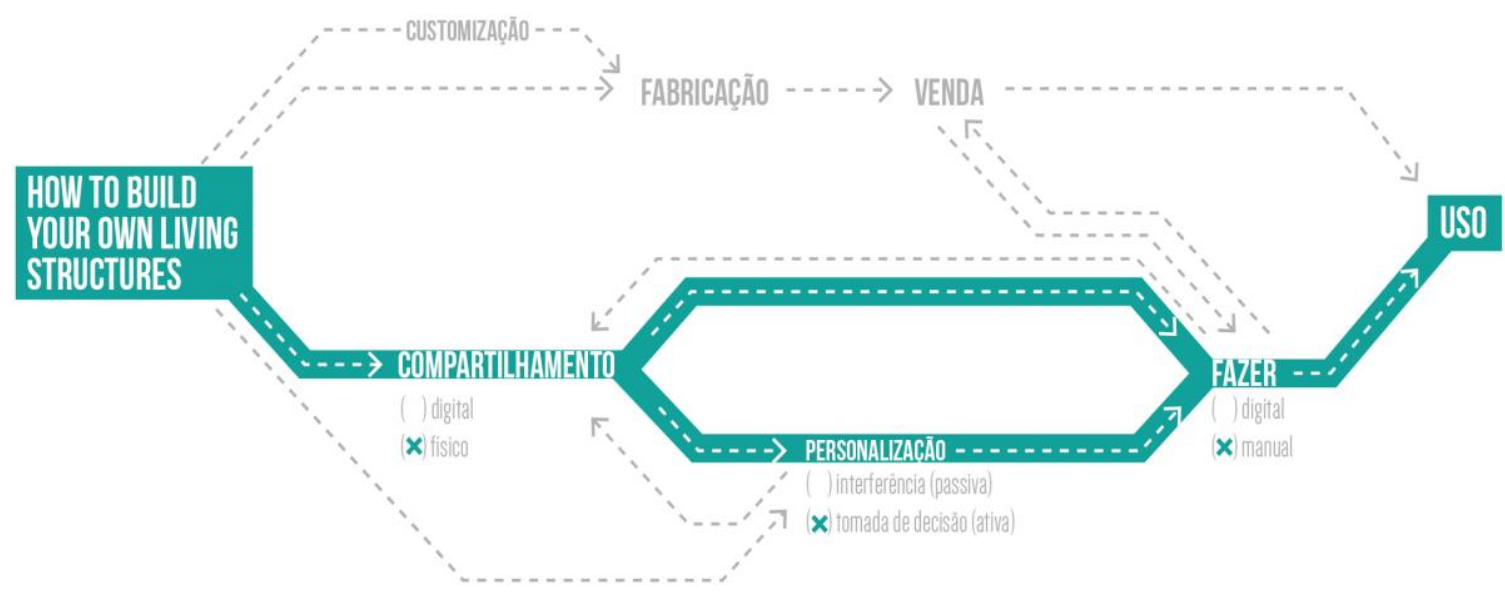

Figura 2: How to build your own living structures. Fonte: autores.

\section{HOW TO BUILD YOUR OWN LIVING STRUCTURES, KEN ISAACS, 1974}

Entre 1968 e 1972 foi publicada uma série de artigos dedicados a instruções de como fazer na revista Popular Science, intitulados Living Structures. Considerados revolucionários para seu tempo por propor uma ruptura baseada na reinvenção da forma, do espaço e do uso dos materiais, objetos e sistemas, Living Structures apresenta uma série de mobiliários e unidades arquitetônicas que apontam alternativas sobre como se pode desenvolver atividades cotidianas, dentro ou fora do ambiente doméstico.

Neste cenário, o designer Ken Isaacs se destaca pelas iniciativas em difundir seus projetos com o objetivo de que fossem apropriados pelas massas. Isaacs publica seu próprio manual DIY em 1974, intitulado How to build your own living structures, no qual ele apresenta, em uma linguagem clara, uma compilação dos projetos que definiram as duas últimas décadas de sua carreira, seguidos de instruções detalhadas, desenhos e listas de materiais, mesclando narrativas pessoais e instruções práticas.

Através da aplicação de um método que substituiria o da produção em massa, a que chama de "instrução em massa", Isaacs divulga projetos de sistemas de morar econômicos no intuito de encorajar uma filosofia do façavocê-mesmo e consequentemente um potencial empoderamento dos consumidores através do ato de fazer. Somando-se a conjuntura da ascensão dos movimentos contraculturais, é possível alinhar de maneira clara as habitações e mobiliários de Isaacs com os princípios alternativos da juventude dos anos 60 e 70, e com a preocupação as consequências de uma sociedade globalizada, mecanizada e baseada na sociedade de consumo. Assim, suas ideias iniciais se agregam a preocupações ecológicas e éticas e são redirecionadas para uma prática que abrangesse alternativas para se viver de maneiras mais flexíveis e sustentáveis.

Para Isaacs, nunca houve dúvida de que o design deveria se basear em um conjunto de objetivos e hipóteses mais palpáveis do que aqueles que impulsionam a produção em massa, e é claro que, apesar da dúvida sobre se a proposição de alternativas deveria partir das bordas do sistema ou do centro, a abordagem para o problema da sobrevivência humana se dá através da proposição de ações concretas e inventivas, mais do que por "fantasias culturais" (Isaacs, 1974, p.85).

Por esse motivo, o grande apelo do trabalho Living Structures pode ser identificado na sua suposta acessibilidade, já que a aplicação da teoria apresentada por Ken Isaacs se dá através de materiais de construção e elementos pré-fabricados comuns, acessíveis e facilmente encontrados (Figura 3), ainda que o sistema possa ser considerado como conceitualmente complexo.
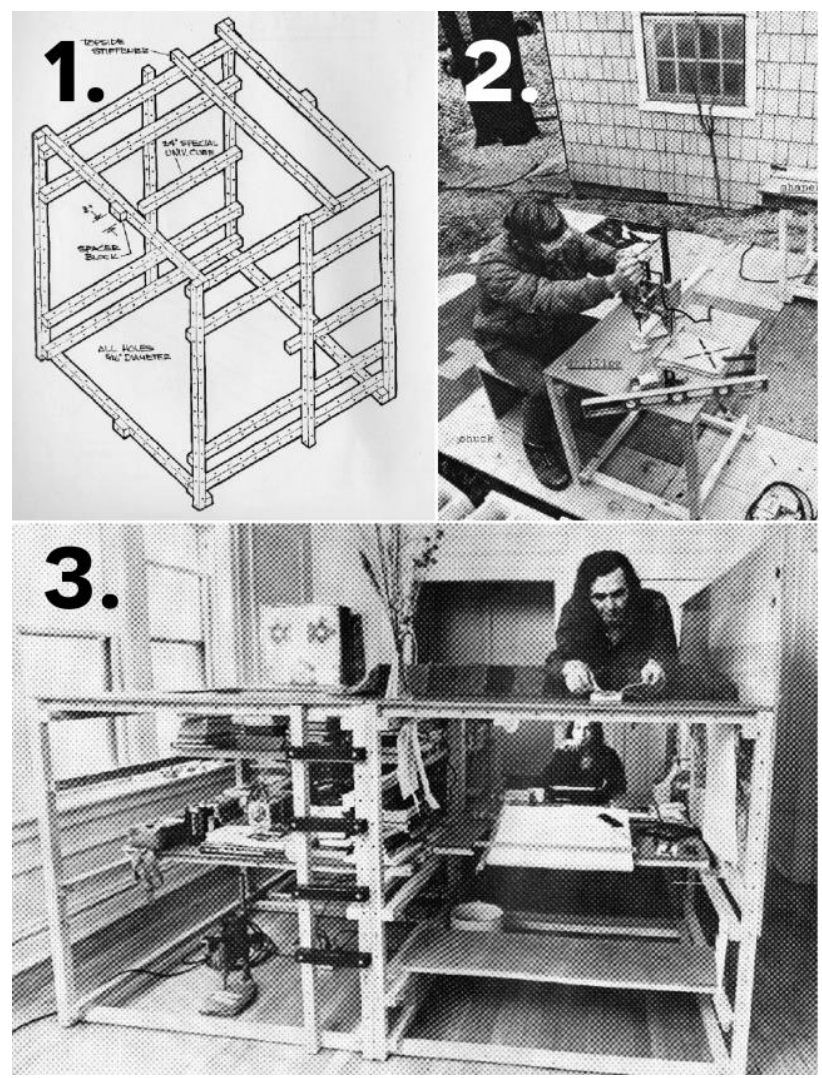

Figura 3: processo produtivo (manual) previsto por How to build you own living Structures. 
Pode-se considerar que a primeira peça referente à série Living Structures de Ken Isaacs data de quando ainda é estudante na Bradley University, em Peoria, momento em que desenvolve explorações arquitetônicas baseadas em módulo de grade. A partir daqui, Isaacs centra praticamente toda sua carreira a (re)imaginar o mobiliário como sistema que se adapta às pessoas mais que elas a ele. Seguindo essa diretriz de criar ambientes mais flexíveis, chegando ao nível da relação entre o mobiliário e o ambiente, ou mesmo ao próprio edifício, Ken e Barbara Isaacs elaboram o que se denominou de sistema Matrix, que se baseia em estruturas em formato de cubos de arestas medindo 48 polegadas, por sua vez confeccionados a partir de elementos estruturais padrão, de seção quadrada ( $2 \times 2$ polegadas), perfurados de acordo com um padrão que permite que se unam sob diversas configurações.

O que o sistema traz como grande novidade em relação aos mobiliários então disponíveis é a flexibilidade a novas situações, uma vez que o sistema de montagem utilizado apresenta relações facilmente modificáveis, adaptáveis e rearranjáveis, mediante aplicação de pouca energia e esforço.

Além disso, Isaacs afirma que a mobília como é encontrada em sua forma tradicional não se encontra organizada como um sistema de fato, mas é composta por amontoados de objetos que não são capazes de estabelecer relações entre si, com vida útil reduzida e, portanto, responsável pela geração de grande quantidade de lixo quando descartada. Por outro lado, um trabalho que se baseie no Matrix se articula por interpenetração de espaços de maneira sistemática e geométrica, compondo um sistema que obtém um melhor aproveitamento do espaço a partir de um leque menor de componentes, tornando-o mais coeso, além de ser composto por elementos que, por se basearem em um sistema modular, permitem uma facilitada readequação do mobiliário, reparos, e o reaproveitamento de suas partes, ampliando a vida útil dos objetos e eliminando, ou ao menos diminuindo, a quantidade de materiais descartados.

Como os módulos são projetados com base na utilização de materiais e ferramentas comuns e de fácil acesso, destaca-se a importância deste projeto no que diz respeito à inclusão dos usuários nos processos de criação e no oferecimento de controle sobre os resultados produzidos, por conta da flexibilidade oferecida pelo sistema, que, por estes motivos, poderia ser considerado como aberto.

\section{A DINÂMICA DO FAÇA-COM-OS-OUTROS VINCULADA À CULTURA DIGITAL}

O conceito de abertura (openess), de acordo com Jos de Mul (2011), estaria se tornando especialmente popular nos anos 90 e 2000, sendo definido como uma posição filosófica genérica de onde organizações e indivíduos operam, geralmente amparados por um processo de tomada de decisão que valoriza mais o gerenciamento comum - usuários e produtores - do que a autoridade centralizada - proprietários e especialistas. O autor cita a Wikipedia como exemplo dos projetos de abertura e é de onde retira, portanto, a definição que para o que viria a ser a abertura (openness), notando que, na sociedade global de informação, o termo se torna um jargão, uma palavra "elegante" típica de um tempo e contexto.

A demanda pela abertura estaria se espalhando pelos mais diversos meios, pressupondo uma forma de produção que estaria ganhando importância devido à transição gradual de modelos fechados dos meios tecnológicos, científicos e culturais para modelos que se colocam como complexos e interdisciplinares, abertos. Um dos recentes incrementos a esta filosofia da abertura seria a emergência dos softwares livres, que se estendem desde sistemas operacionais a uma variedade de outras aplicações menores. Entretanto, a demanda por sistemas abertos não recai apenas sobre o universo dos softwares, mas estaria se expandindo para todo e qualquer conteúdo cultural, em um leque de possibilidades que se abre para a música, filmes e livros, bem como para as áreas científicas, acadêmicas e tecnológicas, por meio de pesquisadores que buscam por acesso livre a publicações e banco de dados.

Para Carolien Hummels (2009), estas manifestações tratam-se de uma frente para o design na qual pessoas de áreas variadas desenvolveriam soluções em conjunto com (e para) uma comunidade supostamente aberta. O objetivo é que não apenas o resultado se apresente como de livre acesso, mas o termo estaria se referindo também a processos de produção, participação de diversos sujeitos e possibilidade de releituras, adaptações e modificações sobre um mesmo projeto. Seguindo o raciocínio do software livre, não bastaria disponibilizar um resultado pronto, mas garantir meios para que também seja possível visualizar e modificar o código que originou o produto final, contribuindo para a ampliação do conhecimento acerca de um determinado problema e possibilitar novas vertentes para sua solução.

\section{A INICIATIVA WIKIHOUSE}

Assim como outras formas de abertura, o conceito de open design (ou ainda design livre, ou aberto) estaria ganhando força a partir das revoluções de comunicação e informação do final do século XX e do aparecimento de equipamentos de produção digitais (o que possibilitaria uma vasta troca de informação através de mídias). O termo está diretamente relacionado (e baseado) em outro, o do open source, que se refere ao movimento responsável pelo início do compartilhamento de códigos fonte de software, dando origem aos chamados softwares livres.

Assim, os princípios do design aberto não visam o oferecimento de produtos gratuitos, mas um modo de produção distinto, cujo objetivo, de acordo com o Instituto Faber-Ludens (2012) - uma entidade sem fins lucrativos que promove o desenvolvimento do Design e da Tecnologia no Brasil - seria garantir quatro liberdades fundamentais: colocar um procedimento em prática, qualquer que seja o propósito; verificar seu funcionamento e adaptá-lo para as próprias necessidades; distribuir cópias; e produzir e distribuir aperfeiçoamentos que possam beneficiar a comunidade.

Ao incorporar estas premissas na esfera do design, é perceptível que 0 design aberto preza pelo compartilhamento de instruções de projeto e formas de produção, de modo que busca gerar conhecimento livre 
sobre os objetos, partindo da suposição de que seriam melhor aproveitados quando produzidos de maneira personalizada pelo próprio usuário.

A iniciativa da WikiHouse se insere neste contexto, uma vez que se intitula um projeto de código aberto e colaborativo, entre outros princípios que corroboram para que seja compreendida nesta esfera. $O$ projeto foi apresentado já em 2013 no TED Talks pelo designer Alastair Parvin, como uma iniciativa inovadora, simples e provocativa, e continua ativo, de forma a permitir colaborações e apropriações. A ideia central se apresenta de forma simplificada: pessoas comuns poderiam projetar e construir suas próprias residências, em qualquer lugar, utilizando-se de um conjunto de informações disponibilizadas na plataforma online oficial do projeto. Para o palestrante, a iniciativa da WikiHouse seria uma solução para que a atividade do arquiteto se estenda de fato a todas as camadas populacionais, e não se restrinja apenas àquelas que podem pagar por seus serviços, pois, quando se fala na profissão do arquiteto, supõe-se que esteja se tratando a respeito de um profissional que, a partir de suas competências, deveria atuar para resolver, ou ao menos minimizar, problemas como as mudanças climáticas, as desigualdades sociais no acesso à habitação e aqueles oriundos dos processos de urbanização.

No âmbito da WikiHouse, três pontos-chave estariam, segundo seu idealizador, colaborando com o intuito de ampliar 0 alcance da atividade arquitetônica. Primeiramente, Parvin esclarece que a arquitetura não é responsável apenas pela construção de edifícios (o edifício, aliás, é encarado como a solução mais cara para o que se propõe a resolver), mas pode se aplicar em outras áreas. Em segundo lugar, afirma que a arquitetura não precisa ser grande, seja em tamanho ou mesmo em custo, para que seja abrangente. Por último, destaca a relevância da participação amadora, que se mostra como o cerne dos movimentos de faça-você-mesmo desde que este surge na década de 60: a pretendida descentralização dos saberes e meios de produção que, desta forma se espalhariam da mão de obra especializada para uma parcela amadora da população, supostamente aumentando os níveis de acessibilidade aos meios projetivos e produtivos.
Entre os objetivos enumerados pelo manual oficial do projeto, Using WikiHouse: an introductory guide for your Project (2018) e pelo próprio site da iniciativa, estão a tentativa em oferecer boas soluções de design para que qualquer cidadão em qualquer parte do mundo construa habitações a baixo custo. $\mathrm{O}$ uso de tecnologias digitais com o intuito de facilitar a produção (fabricação e montagem) de tais residências, de forma sustentável e acessível, e a criação de uma indústria de habitação nova, bem distribuída e com ênfase nas relações locais comunitárias, na tentativa de reduzir a necessidade de sistemas massivos de financiamento, também são listados como objetivos da proposta como um todo.

Percebe-se que a proposta da WikiHouse se baseia em alguns princípios que se aproximam claramente dos veiculados pelo movimento Maker. Assim, seria possível relacionar esta manifestação como uma das vertentes do movimento, se o considerarmos como centralizador das manifestações de faça-você-mesmo contemporâneas.

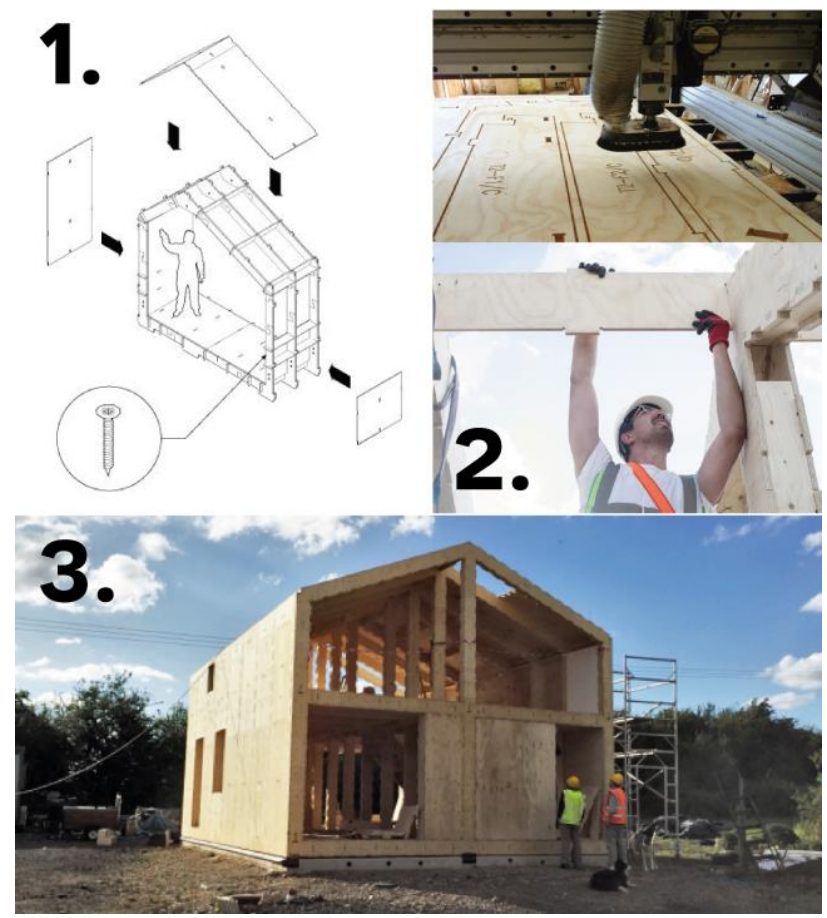

Figura 4: processo produtivo de uma WikiHouse

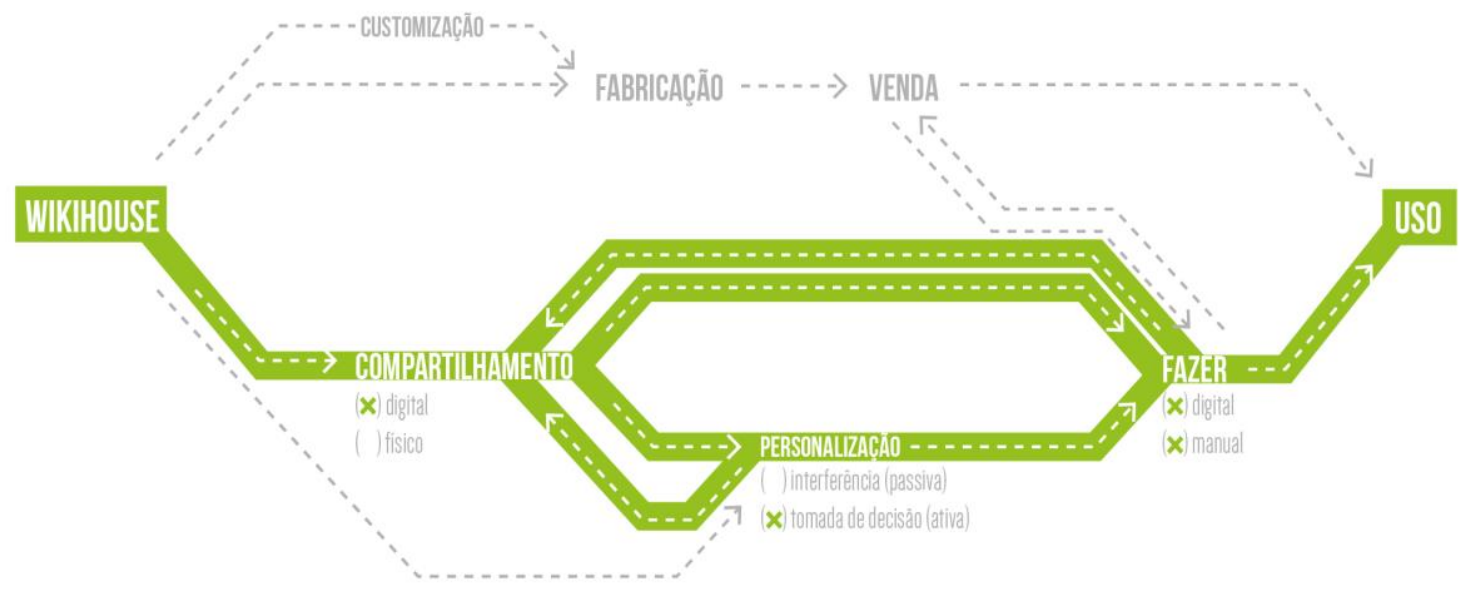

Figura 5: WikiHouse. Fonte: autores. 
Estas, por sua vez, podem aparecer renomeadas como expressões de faça-com-os-outros (ou do-it-with-others, DIWO, como clara alusão à importância das atividades de compartilhamento). Entre eles, a preferência pela produção local, mesmo que o compartilhamento de informações se dê em nível global; a diminuição de custos, recursos, energia e tempo; a utilização de modelos abertos; a fácil manutenção, reutilização, adaptação e reparo, visando o aumento da vida útil dos projetos, em oposição às conhecidas dinâmicas de obsolescência programada praticadas por grandes produtores; a preferência pela reutilização e adaptação de projetos já existentes à criação de algo totalmente novo; e a utilização de materiais de disponibilidade facilitada.

Alastair Parvin compara ainda a WikiHouse com os mobiliários da Ikea, marca conhecida por entregar seus mobiliários desmontados para que sejam montados pelo próprio comprador, em casa. A comparação se dá pelo fato de que o projeto da WikiHouse é compartilhado na forma de peças que, juntamente com instruções para encaixes, devem ser montadas de maneira a conformar 0 produto final. No entanto, ao contrário da dinâmica adotada pela Ikea, as peças da WikiHouse não são entregues fisicamente ao usuário, mas seus códigos são compartilhados livremente de forma que possam ser reproduzidas através da manufatura digital, em maquinários como fresadoras, a partir de matéria prima obtida localmente (Figura 5).

Parvin (2013) afirma ainda que, se a grande questão do século $X X$ era a democratização do consumo, a grande questão do século XXI é a democratização da produção, propósito para o qual, conforme o próprio palestrante afirma, a interação por meio da internet se mostra como uma significativa diferença.

\section{DISCUSSÃO}

Para auxiliar a análise das aproximações e distanciamentos entre os dois objetos de estudo apresentados, bem como possibilitar um exercício comparativo com processos do sistema de manufatura convencional, foram elaborados gráficos que organizam os processos de projeto e produção de cada estudo de caso.

Os diagramas de cada caso se organizam sobre uma base comum aos três, que se estrutura de maneira a ilustrar diferentes processos, e se iniciam indicando a forma com que o projeto em si é veiculado, passando por dinâmicas de produção, para então chegar à etapa da utilização em si. Assim, para cada caso é destacado um percurso no diagrama, que representa a sequência de seus processos produtivos.

O primeiro diagrama representa os processos de manufatura convencionais (Figura 1). Nele, destacam-se quatro etapas principais: projeto, fabricação, venda e uso. Ao analisar os diagramas seguintes (Figuras 2 e 5), fica claro que os dois objetos levantados (o almanaque How to build your own living Structures e a iniciativa WikiHouse) se diferem drasticamente do sistema adotado pela manufatura convencional, ao se encaminharem por uma orientação distinta: os seus fluxos produtivos se iniciam pelos processos de compartilhamento e/ou à personalização, elementos aqui localizados necessariamente em posição anterior ao ato de fazer

Uma vez iniciados a partir do compartilhamento, os processos se diferenciam quanto à sua disponibilização: enquanto o almanaque de Isaacs é compartilhado sob a forma física, impressa (pelo menos na época em que é lançado, visto que hoje também são encontradas versões digitais da publicação), os elementos compartilhados da WikiHouse são distribuídos de maneira digital, através da Internet, sob a forma de download de arquivos.

Outra semelhança é de que ambas as iniciativas permitem personalização por parte dos usuários (que nesta situação estariam se transformando também em produtores). Nos dois casos ela se dá de forma ativa, ou seja, através de uma tomada de decisão do usuário, que opta pela personalização e, principalmente, seria dotado de controle sobre ela na etapa de projeto, pelo menos.

Uma vez feita a escolha pela personalização (que pode ou não ocorrer) segue-se para a etapa do fazer propriamente dito (que não é denominada como fabricação por não estar relacionada aos processos produtivos fabris clássicos). Aqui, os dois casos também se diferenciam: os processos produtivos dos projetos contidos em How to build your own living structures são unicamente artesanais (como esperado de algo idealizado com objetivo de prover acessibilidade irrestrita na década de 70, com o uso apenas de ferramentas manuais), enquanto a WikiHouse é construída tanto em etapas digitais (a reprodução de peças por meio de fresas controladas digitalmente) como manuais (processos de montagem). A principal diferença entre as manifestações, como já indicado por Alastair Parvin, se daria pela presença da internet, que atua como um agente facilitador para o compartilhamento dos projetos, das personalizações e seus resultados, permitindo que o indivíduo fizesse as coisas por si mesmo, mas, principalmente, se relacionasse com outros durante 0 processo, sob uma promessa de que o compartilhamento e a digitalização seriam fatores que contribuem para a melhoria dos sistemas em que se inserem.

Parece claro que os movimentos que se classificam como pertencentes ao universo do design aberto no presente tomam como ponto de partida a característica emancipatória que a atividade estaria trazendo ao usuário (assim como os movimentos contraculturais característicos da década de 60), quando assumem as ferramentas de projeto e produção de uma maneira que se pretende acessível, colaborativa e independente da indústria de massa. Entretanto, é igualmente perceptível que algumas críticas a respeito do movimento têm se delineado, baseando-se em certa distância que por vezes tem se estabelecido entre discursos e práticas. Por exemplo, é passível de questionamento a efetiva abrangência destas expressões que se denominam democráticas e de livre acesso: as ferramentas e saberes necessários para que se coloquem em prática tais iniciativas são de fato acessíveis a todos, em se tratando de equipamentos e saberes necessários? Ou, é possível ainda que tais tentativas acabem por se destinar a um sujeito utilizador dotado de um perfil específico, mais especializado? 
Além disso, ainda que o cerne do movimento maker esteja indicado no trabalho de amadores, o surgimento de novas tecnologias produtivas também estimula 0 aparecimento de pequenas empresas e iniciativas privadas baseadas em inovação, de forma que começa a se tornar perceptível a existência de duas vertentes do movimento maker: uma que almeja a democratização da produção (vinculada a uma crítica à sociedade de consumo), mas também uma que busca aproximar essas novas tecnologias de fabricação de novos modelos de negócios (SODERBERG, 2013). Assim, a cultura maker, por vezes incorporada inclusive por grandes corporações - como se tem observado nos últimos anos -, não responderia mais às suas premissas iniciais e, portanto, necessitaria de uma adaptação na forma como vem sendo conduzida.

Enquanto autores como Peter Troxler (2013) nomeiam esse novo período como a $3^{\underline{a}}$ Revolução Industrial (ou mesmo como a $4^{a}$ ), utilizando o termo em um contexto otimista, é interessante notar que outros, como Felipe Fonseca (2015) por exemplo, começam a olhar os termos com certa dose de crítica: se o que se nomeia como uma nova revolução industrial é resultado, em primeiro lugar, de uma crítica aos processos industriais como vêm sendo desenvolvidos até então, seria incongruente nomear estas novas manifestações (que seriam, ao menos a princípio, disruptivas) sob a mesma lógica de nomenclatura que rege aquele sistema a que elas se opõem, ou seja, é ilógico nomear algo que se opõe à indústria por princípio como uma nova Revolução Industrial.

Colocadas as questões da digitalização e da comunicação em rede como centrais nessas novas formas de produção compartilhada, seria possível pensar outros ciclos para o design, novas possibilidades, sua dimensão social, e apontar caminhos que tensionem o quadro que se configura hoje?

Outro aspecto a se considerar sobre o período em que nos encontramos é de que os encaminhamentos que o design toma a partir da década de 90 configuram uma nova fase para a disciplina, nomeada por Andrew Blauvelt (2010) como "design relacional". O que a difere das anteriores é a ampliação da influência do design para âmbitos que antes se viam excluídos da relação formaconteúdo, como a aproximação com o público utilizador, através de mercadorias endereçadas a públicos muito específicos por meio da customização em massa, por exemplo, ou ainda personalizações através de faça-vocêmesmo, hack de designs já existentes ou plataformas de financiamento coletivo. Tratam-se de respostas a problemas e situações que não puderam ser resolvidos pelos meios convencionais, por serem muito custosos ou complexos.

How to build your own living structures e WikiHouse se assemelham claramente quando ambas se declaram como manifestações anti-sistêmicas, por meio das quais aquele a quem se denomina apenas como indivíduo, ou usuário, se perceberia capaz de se desvincular dos modos de produção convencionais, tornando-se independente deles. Contudo, o reaparecimento da pauta do faça-você-mesmo no presente se mostra permeado por discursos de inovação tecnológica, que, se por um lado representam maior possibilidade de desenvolvimento para os projetos, por outro oferecem a possibilidade da expansão para além do previsto, o que poderia causar torções nas pautas originais do movimento.

A temática da colaboração na atualidade, neste contexto que supostamente se conformou a partir de um conjunto de fatores como avanços tecnológicos e trajetórias de crítica econômica, a partir da década de 90, estaria culminando em um momento em que se identifica determinada assimilação de elementos que eram, na década de 60, anti-sistêmicos. É necessário ter em mente que estes contextos e possibilidades se apresentam de maneira heterogênea, ao se analisarem manifestações que se intitulam como pertencentes a um movimento de abertura do design na atualidade.

\section{AGRADECIMENTOS}

Agradecemos ao Instituto de Arquitetura e Urbanismo (IAU-USP) pelo apoio, e às agências CAPES e CNPq pelo financiamento que permite a execução desta pesquisa (o presente trabalho foi realizado com apoio da Coordenação de Aperfeiçoamento de Pessoal de Nível Superior - Brasil (CAPES) - Código de Financiamento 001.)

\section{REFERÊNCIAS}

Alastair Parvin: Architecture for the people by the people (2013) Retrieved from https://www.ted.com/talks/alastair_parvin_architecture_for_th e_people_by_the_people

Bishop, C (2006). Participation. London: Whitechapel Art Gallery.

Blauvelt, A. (2010). Para um Design Relacional. Revista de Comunicação e Linguagens, Lisboa, n.41, p.45-49.

Cardoso, R. (2013) Design para um mundo complexo. São Paulo: Cosac Naify.

Flynn, K. (2018) Open Source for everyone? Retrieved from http://www.architectmagazine.com/aiaarchitect/aiafuture/open-source-for-everyone_o

Fonseca, F. (2015). Gambiarra: repair culture Leaving the box Entrepreneurship, Innovation and Initiatives. Retrieved from https://issuu.com/tvergasteinjournal/docs/content_final

Foster, H. (2002) Design and Crime: And Others Diatribes. London: Verso.

Garret, M; Catlow, R. (2012) DIWO: Do It With Others - No Ecology without Social Ecology, Remediating the Social. Simon Biggs University of Edinburgh. p.69-74. 2012.

Hummels, C. (2011) Teaching attitudes, skills, approaches, structure and tools. Open Design Now: Why Design Cannot Remain Exclusive. Amsterdam, The Netherlands: BIS publishers.

Isaacs, K. (1974) How to build your own living structures. New York: Crown Publishers.

Kuznetsov, S.; Paulos, Eric. (2010) Rise of the Expert Amateur: DIY Projects, Communities, and Cultures. In: NordiCHI, 10., Nova lorque, 2010. Anais... Nova lorque: ACM, 2010, p. 295304. Retrieved from: http://doi.acm.org/10.1145/1868914.1868950

Jameson, F. (1992) Periodizando os anos 60. In: BUARQUE DE HOLLANDA, Heloísa (Org.). Pós-Modernismo e política. Rio de Janeiro: Rocco.

Mays, J. B. (2014) The dubious rise of open-source architecture. Retrieved from https://www.theglobeandmail.com/life/homeand-garden/architecture/the-dubious-rise-of-open-sourcearchitecture/article20150690/ 
Mul, J. (2011) Redesigning design. In: Open Design Now: Why Design Cannot Remain Exclusive. Amsterdam, The Netherlands: BIS publishers.

Pereira, C. A. M. (1986) O que é contracultura. São Paulo: Nova Cultural/Brasiliense.

Santos, L. G. (2003) Politizar as novas tecnologias: o impacto sócio-técnico da informação digital e genética. São Paulo: editora 34.

Soderberg, J. (2013) A ilusória emancipação por meio da tecnologia. Le Monde Diplomatique Brasil. Retrieved from http://www.diplomatique.org.br/artigo.php?id=1339
Troxler, P. (2013) Making the 3rd Industrial Revolution. The Struggle for Polycentric Structures and a New PeerProduction Commons in the Fab Lab Community. In: Fablab: Of Machines, Makers, and Inventors (Cultural and Media Studies). Bielefeld: Transcript Publishers.

Using WikiHouse: an introductory guide for your project. (2018) Retrieved from

https://s3.eu-west2.amazonaws.com/wikihouse.cc/WHouse_Guide_1.0.pdf

Walter-Herrmann, J.; Büching, C. (2013) FabLabs: Of Machines, Makers and Inventors.Transcript-Verlag 